\title{
HRM system strength - HRM harnessed for innovation, appropriability and firm performance
}

\author{
Pia Hurmelinna-Laukkanen ${ }^{1} \cdot$ Jorge Gomes $^{2 *}$ \\ ${ }^{1}$ Oulu Business School, University of Oulu, Finland \\ ${ }^{2}$ ISEG-Technical University of Lisbon and CIS-ISCTE/IUL, Portugal
}

Received: 28 September 2012

Revised: 29 November 2012

Accepted: 30 November 2012

\begin{abstract}
HRM systems and practices can have a notable impact on a firm's performance. Employees exchange and co-utilize innovation-generating knowledge, leading often to improvements in the firm's financial performance, but they may also (unintentionally) give out valuable information. In this study, we discuss how HRM practices can be designed to foster innovation and at the same time maintain appropriability of innovations. We introduce the concept of HRM Strength to explain how the HRM system may affect people's vision of what is important in a company. Questionnaire data from 89 Finnish firms were utilized. The results indicate that HRM Strength is related to financial performance, both directly and indirectly. Implications of these results are discussed and future work is suggested.
\end{abstract}

Keywords: strategic HR, innovativeness, appropriability, performance, HR strength JEL Classification Codes: M20, O34, D23, D24

\section{Introduction}

In the last two decades both academics and managers have become interested in strategic HRM (SHRM). It is argued that if managed strategically, employees and the HRM system and practices contribute to competitive advantage, and to achieving the company's goals and values (Becker and Huselid, 1998).

The existence of this relationship has received some empirical support already, (e.g., Ferris et al. 1999) but only recently authors have started to explain how this connection works. While in the past the trend has been on a systems view of HRM (configurations of HRM practices) or on the fit between various HRM practices and a firm's competitive strategy (see, e.g., Lengnick-Hall and Lengnick-Hall, 1999), examination of the effects of specific HRM practices and the ways in which employees can be guided and motivated to adopt preferred

*Corresponding author. E-mail: jorgegomes@iseg.utl.pt.

Citation: (2012) HRM system strength - HRM harnessed for innovation, appropriability and firm performance, Economics and Business Letters, 1(4), 43-53. 
attitudes and behaviours seems to be a new and quite fertile ground. In this respect, Guest (2011) has pointed to the process-view of HRM (e.g. Bowen and Ostroff, 2004; Li et al., 2011) as a novel and powerful view to explain how employees' motivation and other outcomes (e.g. innovativeness) can be linked to how (process) the HRM function communicates with employees, rather than to what (content) it communicates to them.

In line with the SHRM view, and influenced by the recent stream of literatures advocating the development of innovative environments, one can conjecture that HRM should foster innovation, and improve firm performance. For this, the HRM system needs to be harnessed simultaneously for the creation of innovative environments with extensive knowledge exchange, and, on the other hand, for appropriability and protection issues (see e.g., Cohen et al. 2000) involved in most creative endeavours. These aspects of innovativeness and appropriability (e.g., based on legal protection of innovative creations) are not completely without contradictions, and balancing and compromises are needed.

This interplay between human and legal issues in innovation has been rarely explored in the literature (Hannah, 2005), and it introduces a contingency element in the view that HRM should support a particular strategy without hesitation. Our discussion addresses how HRM can be designed to communicate a dual message: if on one hand employees should strive for innovativeness, they nevertheless need to maintain security about the ideas generated and projects developed. The remaining of this text consists of theoretical considerations and an empirical study aimed at exploring these ideas and relationships.

\section{Framing views through HRM}

\subsection{Opening the black box}

"How much does human resource management matter?" is the question with which Gerhart, Wright and McMahan open their 2000 article. This question reflects much of the debate in the recent HRM literature, as the personnel function is increasingly called to both show how it can contribute to boost individual and organisational productivity and achieving organisational goals. These concerns have been at the core of an important stream of research in HRM since early 1990s, currently known as the Strategic HRM perspective (Becker and Gerhart, 1996; Wright and McMahan, 1999).

The implicit assumption of this perspective is that if HRM is conducted well, this will somehow make organisations perform more effectively (Ferris et al., 1999). The key issue is captured by the word 'somehow'. In fact, notwithstanding the theoretical and empirical support to the relationship between HRM and organisational performance, there is a significant lack of knowledge with regards to how such connection works.

Several scholars and managers have devoted time and efforts to understand such connections between HRM, strategy, and performance. An important proposal by Bowen and Ostroff (2004) suggests that the relationship between HRM and performance is mediated by the psychological interpretation of events, and, in particular by the degree to which people diverge or converge in their views of the situations. This convergence is called psychological strength (Mischel, 1973). In strong psychological situations people share interpretations of particular events, therefore behaving in a uniform and consistent way, and showing a similar orientation towards goals and desired standards and performance. On the contrary, in weak situations people interpret their surroundings in many dissimilar ways, hence exhibiting different behaviours and actions. 


\subsection{Strength of the HRM system}

Bowen and Ostroff (2004) pick up these ideas, and advance the concept of HRM strength. The authors build on Kelley's attribution theory (1967), in which people are said to form attributions about cause-effect relationships in situations depending on the degree of distinctiveness, consistency, and consensus. Bowen and Ostroff define a set of nine unique attributes, which are related to the HRM process: Distinctiveness (the degree to which a situation stands out in the environment, thereby capturing attention and arousing interest) encloses the first four attributes: Visibility defines the degree to which HRM practices are salient and readily observable. Understandability refers to the way in which different workers categorize the information gathered from each HRM practice. Legitimacy of authority is related to the perceived power of HRM in the organization, namely the prestige of top HR managers and the influence of HRM in determining the mission and aims of the organization, and, fourth, relevance refers to the linkage between a situation and a goal. Consistency relates to how consistent relationships are over time, people and contexts. It is composed of the next three attributes: Instrumentality refers to the perceived cause-effect relationship between personal behaviours and rewards, which are stimulated by HRM practices. Validity is concerned with the degree to which expected behaviours are rewarded by the HRM system. Consistent HR messages refer to the degree to which HRM practices convey similar and consistent messages across the organization and across time. Finally, Consensus is the degree of agreement among employees, and it captures the last two attributes: Agreement among principal HR decision makers deals with the degree to which workers perceive agreement across HR top decision makers, and fairness refers to perceived justice in the use of HRM practices.

\section{Innovation creation, value capturing and HRM systems}

\subsection{HRM system and generating innovation}

Distinctiveness, consistency, and consensus refer to the communication process through which HRM sends its messages to people and shapes their views of what is wanted from them. This can be highly relevant when the aim is to improve a company's innovative performance. For example, performance appraisal and compensation systems can and should be carried out and communicated in a way promoting innovation as the main message that employees get from the HRM system.

Innovative performance of a company naturally depends on various factors. However, acquiring, sharing, and utilizing knowledge are highlighted in many studies (Huber, 1991; Zahra and George, 2002). Knowledge needs to be gathered from internal and external sources, it has to be converted into forms in which it can be transferred and shared, and it needs to be exploited to create innovations. For all this to happen, the HRM system needs to be paid attention to. Recognition and retention programs are one area that allows firms to reward and reinforce preferred behaviours (Ford and Fina, 2006), and in effect, strengthen the HRM system - if the rewarding systems, for example, are seen as fair and consistent. The same reasoning can be extended to other practices, such as training and education, performance appraisal, compensation, benefits, and careers. The more important innovation is perceived by employees, the more likely they engage in fostering and nurturing a climate that really supports knowledge sharing and innovativeness. If there are employees that do not consider knowledge transferring important or rather concentrate on doing what has always been done (e.g., due to the incentive system rewarding for consistent good quality instead of innovation that may represent certain disruptions quality wise), the aims of the firm in terms of 
increasing innovativeness are likely undermined. In line with these considerations, the following hypothesis can be introduced:

\section{H1: HRM Strength is positively related to innovativeness}

\subsection{HRM in the protection of company specific knowledge and innovations}

Companies possess great amounts of innovation-related knowledge that they want to keep proprietary. Some of this knowledge can be covered with exclusive rights, which allows a firm to be a sole beneficiary of intellectual property at least a period of time, even if central parts of know-how would be disclosed in, e.g., patent applications. On other cases, secrecy or lead time is preferred or the only alternative. The benefit from using such mechanisms is that innovativeness can be fostered: incentives to produce new innovations are higher when there are better prospects to gain return on the made investments, and it also is easier to connect with other organizations for access to new knowledge needed to generate innovation, and commercialization channels for innovations (e.g., van Vijk, 2000; Hurmelinna-Laukkanen and Puumalainen, 2007). Subsequently, the following can be hypothesized:

\section{H2a: The strength of appropriability regime is positively related to innovativeness}

Irrespective of the used means of protection, keeping the knowledge-based advances created within a firm requires relying on employees. As Baughn et al. (1997, p.105) note, "HR practices and active monitoring of knowledge flows and information requests are key to keeping intellectual capital protected".

In order to achieve proper appropriability regime consisting of different protection mechanisms (see Hurmelinna-Laukkanen and Puumalainen, 2007), the employees need to act according to protective needs of the firm. Employment legislation in itself is one protection mechanism: The norms of legislation on employment typically include a duty of loyalty that lasts during the employment relationship, and they also provide a chance to use noncompetition contracts that may make leaving the firm a more unattractive choice (see Rousseau and Wade-Benzoni, 1994, on different types of employment contracts). In fact, the (im)mobility of human resources is important in terms of keeping knowledge and skills in the company: despite causal ambiguity and social complexity, key employees will become visible to competitors, who may try to recruit them (Boxall, 1998). Besides the legal tools, different option arrangements and other such HR practices may enhance employees' willingness to stay. Also, the employer's right of direction in appointing tasks to the employees is important in terms of capturing value: The scale and scope of employees' communication is an essential factor in preventing unintended knowledge flows (Liebeskind, 1997), and by instructing employees such issues can be better controlled. Collective labour agreements may improve efficiency in protecting knowledge, e.g., through defining which rights belong to the employer and how ideas in employees heads are turned into patent applications. Similarly, rules for transferring intellectual property rights (IPRs; consider, e.g., regulation on employment inventions or on rights to works of art created during employment) from individual employees to the firm is based on existence of employment relationships. Signing non-disclosure agreements reminds the employees of their obligations related to information disclosures and preserving trade secrets, and signals the employer's intent to keep certain information confidential (Morehead Dworkin and Callahan, 1998). Further, hiring and firing practices and personnel rotation may be relevant in terms of knowledge protection: employees need to be reminded that they cannot utilize the trade secrets of a firm after they leave the 
company, and when, for example, contact persons in collaboration are changed frequently, tacit knowledge is less likely to transfer between companies (Boxall, 1998).

In sum, the protective strength of all the appropriability mechanisms (IPRs, contracts, labour legislation, tacitness, lead time, secrecy, HRM) can be affected by the willingness and ability of employees to act according to firm goals. Only when all employees understand the need to keep certain knowledge within the firm, protective measures taken can reach their full potential. Based on this, the following hypothesis is drafted:

\section{H2b: HRM Strength is positively related to the strength of innovation appropriability}

\subsection{HRM system for dilemmatic messages}

Considering the messages that are sent in relation to innovation creation and knowledge protection, it can be said that both are clear on their own, first one being "share knowledge to improve innovation performance" and the second one "protect knowledge to improve innovation performance and competitive advantages". Presented simultaneously, they may become dilemmatic, providing contradicting guidelines. The HRM system is responsible for finding and conveying a balance between fostering innovation inside, and keeping the external world from what is going on: the employees of the firm need to know when and how to keep the knowledge protected, and have same knowledge of this. A careful approach is surely needed, especially as poorly distributed HRM messages with regard appropriation (especially with over-protection emphasis present) easily have adverse effects, preventing knowledge flows necessary for creating new innovations (Norman, 2002; Hannah, 2005), or discouraging the willingness of the employees to stay and implement their duty of loyalty (Rousseau and Wade-Benzoni, 1994) - in which case just one employee can cause serious damage for competitive advantage based on innovation by leaking out information, being it an intentional or unintentional action.

Following the notion on competitive advantage, one more area can be explored: While it surely is relevant to know how to align knowledge sharing and protection for better innovativeness, also other performance issues should be of interest. The strength of appropriability regime (stronger protection against imitation and higher exploitability of the innovation) might yield higher financial performance based on exclusivity. Likewise, innovativeness, defined as an ability to produce notable advances to current products/services of a company, can naturally translate into better performance in terms of income, market share and profitability of the firm, for example. This may take some time as innovation and R\&D typically take resources first and only later start to become profitable, but the relationship still may exist. Finally, the HRM system may directly contribute to better turnover and profitability, reflecting the success in aligning the dilemmatic messages. The following hypotheses explore these issues:

H3a: The strength of appropriability regime is positively related to financial performance

H3b: Innovativeness is positively related to financial performance

H3c: HRM Strength is positively related to financial performance 


\section{Method}

\subsection{Data collection}

A questionnaire was prepared and sent to 495 Finnish firms that were customers of a corporation providing modern business premises (together with business and development services) for high tech firms. 89 questionnaires were received. 69 of these had adequate valid data (14\% return rate) and only those were utilized in the actual analysis. The firms represent distinct industries: information and communication technologies, construction, medical devices, and consulting. Table 1 below shows some descriptive statistics.

Table 1. Descriptive statistics

\begin{tabular}{lcccc}
\hline \hline & Personnel & Turnover 2007 & Age & $\begin{array}{c}\text { R\&D intensity } \\
(\% / \text { turnover } \\
\text { allocated to R\&D) }\end{array}$ \\
\hline \hline Mean & 195 & 15984 & 12.41 & 18.53 \\
S.D. & 953.8 & 78967.11 & 14.29 & 23.41 \\
\hline \hline
\end{tabular}

\subsection{Measures}

All items composing the questionnaire required respondents to rate the degree to which they disagree or agree with a particular statement. A 1-5 Likert type of scale was applied for the following measures.

Financial performance was measured as a mean of four items (alpha $=0.746$ ). The performance measure introduced by Delaney and Huselid (1996) was adopted and modified for this purpose. The variable is subjectively assessed, since the respondents were asked to evaluate the performance of the firm compared to other firms in the same or similar business. The dimensions considered for financial performance were growth of turnover, profitability, market share, and financial income from innovation.

Innovativeness was measured as a mean of two items (0.802). The ideas presented in Alegre and Chiva (2008) were adopted and the items were matched to those covering financial performance. The respondents assessed their ability to produce new innovations and innovativeness of their products and services against the similar features of their competitors.

Strength of appropriability regime followed and built on Yale and Carnegie Mellon surveys (Levin et al. 1987, Cohen et al. 2000). Items evaluated a set of protective mechanisms in terms of how well they had protected the company's innovations during the last three years. The five point Likert-scale was modified so that a scale from 0 to 4 was used; 0 indicated that such a mechanism was not applicable and 1-4 showed the protective power of the mechanism, 4 being the strongest. In the questionnaire, three items corresponded to one appropriability mechanism (e.g., patents, copyrights and trademarks for IPR) except for tacitness, for which six items were included in order to capture the different elements of tacitness identified by Zander and Kogut (1995). Since variable "appropriability regime" is a combination of several mechanisms, an aggregated measure was used. Cronbach alpha for this aggregated value was 0.812. Alphas for the various appropriability mechanisms ranged from 0.564 (strength of contracts) to 0.786 (strength of lead time).

Finally, a measure was formed for HRM Strength. Our construct model requires that employees provide their perceptions about the attributes against some anchor point, such as an HR practice. Since performance appraisal is a regular activity carried out by the HR function, it is likely that employees have a more or less fresh recall about this practice. Selection, for example, is not a good anchor point, since most employees have direct contact with such practice only when they enter the organisation. This was indeed confirmed in a set of 
interviews carried out with HR managers; hence performance appraisal was selected as the framework on which items could be generated to assess Bowen and Ostroff's (2004) attributes. Following classical psychometric indications (e.g., Nunnally and Bernstein, 1996), a set of 54 sentences measuring the overall HRM Strength concept were created and tested (Cronbach's alpha: above 0.90).

\section{Results}

\subsection{Hypotheses}

We first performed a set of correlation analyses between the main variables (appropriability regime, HRM Strength, and financial and innovation performance). We then explored associations between the subscales (appropriability and HRM Strength). Table 2 shows correlation values between the main variables.

Table 2. Correlation matrix

\begin{tabular}{|c|c|c|c|c|c|}
\hline & $\begin{array}{l}\text { Mean } \\
\text { (S.D.) }\end{array}$ & Appropriability & HRM Strength & $\begin{array}{c}\text { Financial } \\
\text { performance }\end{array}$ & $\begin{array}{l}\text { Innovation } \\
\text { performance }\end{array}$ \\
\hline Appropriability & $\begin{array}{c}2.00 \\
(0.642)\end{array}$ & & $0.257 * *$ & $0.347 * * *$ & 0.274 \\
\hline HRM Strength & $\begin{array}{c}3.26 \\
(0.846)\end{array}$ & & & $0.345 * * *$ & 0.202 \\
\hline $\begin{array}{l}\text { Financial } \\
\text { performance } \\
\text { Innovation } \\
\text { performance }\end{array}$ & $\begin{array}{c}3.30 \\
(0.787) \\
3.68 \\
(0.818)\end{array}$ & & & & 0.152 \\
\hline
\end{tabular}

$* * *$ and $* *$ Significant at $1 \%$ and $5 \%$ respectively

These results show that while $\mathrm{H} 2 \mathrm{a}$ and $\mathrm{H} 2 \mathrm{~b}$ are supported, $\mathrm{H} 1$ is not. $\mathrm{H} 3 \mathrm{a}$ is supported by the data, and the same is true of $\mathrm{H} 3 \mathrm{c}$, whereas no support can be found for $\mathrm{H} 3 \mathrm{~b}$. In order to explore these results further, two multiple regression analyses were performed. The first one tested financial performance as a measure of HRM Strength, appropriability regime, and innovativeness within a firm. The results indicate that financial performance is positively affected by HRM strength and appropriability (t-test values shown in table 3 ). The second analysis looked into innovativeness as a measure of both HRM strength and appropriability regime. Only appropriability plays a minor role.

Table 3. Regression analysis

\begin{tabular}{lcc}
\hline \hline & Financial performance & Innovation performance \\
\hline \hline HRM Strength & $2.32 * *$ & 1.16 \\
Appropriability & $2.89 * *$ & $1.96^{* *}$ \\
Innovation performance & 0.19 & \\
& & \\
$\mathrm{R}^{2}$ & 0.191 & 0.094 \\
$\mathrm{~F}$ & $5.113 * * *$ & 3.406 \\
\hline \hline
\end{tabular}

$* * *$ and $* *$ Significant at $1 \%$ and $5 \%$ respectively 


\subsection{Exploratory procedures}

Besides studying the hypotheses as such, they can be approached by dividing HRM Strength into its dimensions and by examining their effects on the different variables. This should reveal whether HRM Strength at its best fosters innovation and competitive advantage in any situation. For this, also appropriability regime was divided into its elements. Table 4 below shows some basic information on the dimensions.

Table 4. Dimensions of appropriability and HRM strength

\begin{tabular}{|c|c|c|c|c|c|}
\hline \multicolumn{6}{|l|}{ HRM Strength } \\
\hline & Visibility & Understandability & $\begin{array}{l}\text { Legitimacy of } \\
\text { authority }\end{array}$ & Relevance & Instrumentality \\
\hline Mean & 3.15 & 2.98 & 3.15 & 3.25 & 3.2 \\
\hline \multirow[t]{2}{*}{ S.D. } & 1.053 & .975 & .925 & .862 & .838 \\
\hline & Validity & $\begin{array}{c}\text { Consistent HRM } \\
\text { messages }\end{array}$ & $\begin{array}{c}\text { Agreement } \\
\text { among principal } \\
\text { message senders }\end{array}$ & $\begin{array}{l}\text { Fairness of } \\
\text { the HRM } \\
\text { system }\end{array}$ & \\
\hline Мean & 3.49 & 3.31 & 3.33 & 3.47 & \\
\hline S.D. & .777 & .873 & .952 & .802 & \\
\hline \multicolumn{6}{|l|}{ "Appropriability } \\
\hline & IPR protection & Contracts & Labour legislation & HRM & Secrecy \\
\hline Mean & 1.25 & 2.07 & 1.38 & 2.50 & 1.72 \\
\hline \multirow[t]{2}{*}{ S.D. } & 1.002 & 0.928 & 1.000 & .932 & 1.093 \\
\hline & Lead time & Tacitness & & & \\
\hline Mean & 2.86 & 1.85 & & & \\
\hline S.D. & .877 & .879 & & & \\
\hline
\end{tabular}

The first set of correlations aimed at exploring which of the nine attributes is more associated with innovation performance and financial performance As far as innovation performance is concerned, only understandability $(r=0.242)$, instrumentality $(r=0.314)$, and fairness $(r=0.269)$ show significant correlations. The associations with financial performance are higher, ranging from 0.262 (visibility) and 0.372 (relevance and consistent HR messages). Only instrumentality does not hold a significant correlation with financial performance. All together, these results suggest that HRM Strength and its dimensions do have an impact on innovation and especially on financial performance of a firm.

The second set of correlations explored the links between HRM Strength and appropriability regime. All sub-scales of the two aggregated constructs were correlated with each other. The results show that three subscales of the appropriability regime construct have significant and relevant associations with the subscales of the HRM Strength construct: contracts, labour legislation, and HRM as an appropriability mechanism (note that here HRM Strength refers to HRM related mechanisms that enable blocking knowledge flows; the found correlation thus indicates that the stronger the HRM system is in general, the better gatekeepers the employees are). Only instrumentality is without connection to appropriability mechanisms.

\section{Discussion and conclusions}

The findings from the empirical work and theoretical considerations highlight the importance of HRM Strength. Strength is needed from the HRM system, since dealing with contradictory issues is not uncommon in the present day business environments (consider, e.g. the 
innovation networks where simultaneous autonomy and interdependence, stability and dynamism, knowledge protection and sharing are needed). Communicating in such an environment through HRM practices is not an easy task. For example, according to Rousseau and Wade-Benzoni (1994, p.465), "alignment of business and HR strategies is a key issue in implementing strategy, yet misalignment is common." Therefore, increasing understanding of the premises of building a strong HRM system is relevant.

In our empirical examination we were able to show the influence effect of HRM Strength. In particular, it contributes to financial performance directly, and it is also positively related to the strength of appropriability regime, which, for its part, is linked to innovativeness and financial performance. HRM Strength and its effect on appropriability regime is particularly relevant considering the appropriability regime's role in making sure that innovations can be profited from. This also relates to our finding according to which HRM Strength is most strongly related to strength of contracts, HRM protection, and labour legislation: such mechanisms have been identified as important, but yet the weakest ones in prior studies. If HRM Strength indeed can improve the protective power of these mechanisms, companies have a chance to improving their overall appropriation possibilities.

Besides financial performance, it can be noted that the HRM system also plays a role in relation to innovation activities: while we could not find a relationship between HRM Strength and innovativeness, there were significant positive correlations between certain subdimensions of HRM Strength and innovativeness. In fact, considering all nine subdimensions, understandability (as a part of distinctiveness), instrumentality (as a part of consistency) and fairness (part of consensus), may be the most important ones for supporting innovativeness. For example, while legitimacy of authority might not play such a big role when innovativeness is of concern, instrumentality might be highly relevant considering the fact that wrong kind of incentives may actually kill emergence of innovations (see the discussion above), and fairness might have more emphasis with regard to incentives for innovation than consensus among principal HR decision makers. Nevertheless, deeper analysis is needed in this respect, like considering the relationships between different appropriability mechanisms and HRM dimensions: further research is needed not least because of the linkages between appropriability regime and innovative performance that suggest that (certain dimensions of) HRM Strength may be indirectly related to innovativeness. Especially the relationships between HRM Strength, HRM and lead-time among appropriability mechanisms, innovativeness, and financial performance are worth further examination.

Not finding support for the hypothesis suggesting a relationship between innovativeness and financial performance can be explained by the fact that innovativeness may have even negative effects on profitability, for example: if a lot of resources are put to R\&D and innovation activities, high costs compared to the profits may emerge - at least in the first phases of product life cycle. This may be the case among the firms in our sample, many of which are small start-ups. Nevertheless, deeper examination of these relations may reveal the underlying reasons better.

The theoretical and conceptual development, together with preliminary empirical evidence on the role of HRM Strength, offers tools for gaining deeper understanding on the relationships between the varying factors. In particular, it can be suggested that managers take care of the different areas of HRM system in order to improve its overall strength: distinctiveness, consistency and consensus all seem to be beneficial in an economy where contradictions and paradoxes are faced on day to day basis. Despite the limitations (e.g. small data set, lack of wide-ranging set of control variables) we have provided in this study one point of departure for further work. 
Acknowledgements. We thank the anonymous reviewers for their thoughtful and constructive comments.

\section{References}

Alegre, J. and Chiva, R. (2008) Assessing the impact of organizational learning capability on product innovation performance: an empirical test, Technovation, 28(6), 315-326.

Baughn, C.C., Stevens, J.H., Denekamp, J.G. and Osborn, R.N. (1997) Protecting intellectual capital in international alliances, Journal of World Business, 32(2), 103-117.

Becker, B.E. and Gerhart, B. (1996) The impact of human resource management on organizational performance: progress and prospects, Academy of Management Journal, 39(4), 779-801.

Becker, B.E. and Huselid, M.A. (1998) High performance work systems and firm performance: a synthesis of research and managerial implications, Research in Personnel and Human Resources Management, 16, 53-101.

Bowen, D.E. and Ostroff, C. (2004) Understanding HRM-Firm performance linkages: the role of the "strength" of the HRM system, Academy of Management Review, 29(2), 203-221.

Boxall, P. (1998) Achieving competitive advantage through human resource strategy: towards a theory of industry dynamics, Human Resource Management Review, 8(3), 265-288.

Cohen, W.M., Nelson, R.R. and Walsh, J.P. (2000) Protecting their intellectual assets: appropriability conditions and why U.S. manufacturing firms patent (or not), Working Paper 7552, National Bureau of Economic Research, Inc.

Delaney, J.T. and Huselid, M.A. (1996) The impact of human resource management practices on perceptions of organizational performance, Academy of Management Journal, 39, 949-969.

Ferris, G.R., Hochwarter, W.A., Buckley, M.R., Harrell-Cook, G. and Frink, D.D. (1999) Human resource management: some new directions, Journal of Management, 25, 385415.

Ford, E.L. and Fina, M.C. (2006) Leveraging recognition: noncash incentives to improve performance, Workspan, 11, 19-22.

Gerhart, B., Wright, P.M. and McMahan, G.C. (2000) Measurement error in research on the human resources and firm performance relationship: further evidence and analysis, Personnel Psychology, 53, 855-872.

Guest, D. (2011) Human resource management and performance: still searching for some answers, Human Resource Management Journal, 21(1), 3-13.

Hannah, D.R. (2005) Should I keep a secret? The effects of trade secret protection procedures on employees' obligations to protect trade secrets, Organization Science, 16(1), 71-84.

Huber, G.P. (1991) Organizational learning: the contributing processes and the literatures, Organization Science, 2, 88-115.

Hurmelinna-Laukkanen, P. and Puumalainen, K. (2007) The nature and dynamics of appropriability - Strategies for appropriating returns on innovation, $R \& D$ Management, 37(2), 95-112.

Lengnick-Hall, C.A. and Lengnick-Hall, M.L. (1999) Strategic human resource management: a review of the literature and a proposed typology, in Schuler, R.S. and Jackson, S.E. (eds.) Strategic Human Resource Management, Blackwell Publishers, MA, USA.

Levin, R.C., Klevorick, Alvin K., Nelson, R.R. and Winter, S.G. (1987) Appropriating the returns from industrial research and development, Brookings Papers on Economic Activity, 3, 783-831. 
Liebeskind, J. (1997) Keeping organizational secrets: protective institutional mechanisms and their costs, Industrial and Corporate Change, 6(3), 623-663.

Li, X., Frenkel, S. and Sanders, K. (2011) Strategic HRM as a process: how HR system and organizational climate strength influence Chinese employee attitudes, International Journal of Human Resource Management, 22(9), 1825-1842.

Mischel, W. (1973) Toward a cognitive social learning conceptualization of personality, Psychological Review, 80, 252-283.

Morehead-Dworkin, T. and Callahan, E.S. (1998) Buying silence, American Business Law Journal, 36(1), 151-191.

Norman, P. (2002) Protecting knowledge in strategic alliances. Resource and relational characteristics, Journal of High Technology Management Research, 13, 177-202.

Nunnally, J.C. and Bernstein, I.H. (1996) Psychometric Theory, $3^{\text {rd }}$ ed., McGraw-Hill.

Rousseau, D.M. and Wade-Benzoni, K.A. (1994) Linking strategy and human resource practices: how employee and customer contracts are created, Human Resource Management, 33(3), 463-489.

van Dijk, M. (2000) Technological regimes and industrial dynamics: the evidence from Dutch manufacturing, Industrial and Corporate Change, 9(2), 173-194.

Wright, P.M. and McMahan, G.C. (1999) Theoretical perspectives for strategic human resource management, in Schuler, R.S. and Jackson, S.E. (eds.) Strategic Human Resource Management, Blackwell Publishers, Massachusetts, USA.

Zahra, S.A. and George, G. (2002) Absorptive capacity: a review, reconceptualization and extension, Academy of Management Review, 27(2), 185-203.

Zander, U. and Kogut, B. (1995) Knowledge and the speed of the transfer and imitation of organizational capabilities: an empirical test, Organization Science, 6(1), 76-92. 